\title{
Biomethanation of Carbon Monoxide by Hyperthermophilic Artificial Archaeal Co-Cultures
}

\author{
Aaron Zipperle ${ }^{1,+}{ }^{\circledR}$, Barbara Reischl ${ }^{1,2,+}$, Tilman Schmider ${ }^{1}$, Michael Stadlbauer ${ }^{1}$, Ivan Kushkevych ${ }^{3}{ }^{(0)}$, \\ Christian Pruckner ${ }^{1}$, Monika Vítězová ${ }^{3}$ (D) and Simon K.-M. R. Rittmann 1,2,*(D) \\ 1 Archaea Physiology \& Biotechnology Group, Department of Functional and Evolutionary Ecology, \\ Universität Wien, 1030 Wien, Austria; aaronzipperle@gmail.com (A.Z.); barbara.reischl@univie.ac.at (B.R.); \\ tilman.schmider@uit.no (T.S.); a01005948@unet.univie.ac.at (M.S.); greeese@gmail.com (C.P.) \\ 2 Arkeon $\mathrm{GmbH}, 3430$ Tulln an der Donau, Austria \\ 3 Department of Experimental Biology, Faculty of Science, Masaryk University, 62500 Brno, Czech Republic; \\ kushkevych@mail.muni.cz (I.K.); vitezova@sci.muni.cz (M.V.) \\ * Correspondence: simon.rittmann@univie.ac.at; Tel.: +43-4277-76513; Fax: +43-4277-876513 \\ + These authors contributed equally to this work.
}

check for updates

Citation: Zipperle, A.; Reischl, B.; Schmider, T.; Stadlbauer, M.; Kushkevych, I.; Pruckner, C.; Vítězová, M.; Rittmann, S.K.-M.R. Biomethanation of Carbon Monoxide by Hyperthermophilic Artificial Archaeal Co-Cultures. Fermentation 2021, 7, 276. https://doi.org/ $10.3390 /$ fermentation7040276

Academic Editor: Christian Kennes

Received: 18 October 2021

Accepted: 22 November 2021

Published: 25 November 2021

Publisher's Note: MDPI stays neutral with regard to jurisdictional claims in published maps and institutional affiliations.

Copyright: (c) 2021 by the authors. Licensee MDPI, Basel, Switzerland. This article is an open access article distributed under the terms and conditions of the Creative Commons Attribution (CC BY) license (https:/ / creativecommons.org/licenses/by/ $4.0 /)$.

\begin{abstract}
Climate neutral and sustainable energy sources will play a key role in future energy production. Biomethanation by gas to gas conversion of flue gases is one option with regard to renewable energy production. Here, we performed the conversion of synthetic carbon monoxide (CO)-containing flue gases to methane $\left(\mathrm{CH}_{4}\right)$ by artificial hyperthermophilic archaeal co-cultures, consisting of Thermococcus onnurineus and Methanocaldococcus jannaschii, Methanocaldococcus vulcanius, or Methanocaldococcus villosus. Experiments using both chemically defined and complex media were performed in closed batch setups. Up to $10 \mathrm{~mol}_{\mathrm{C}} \mathrm{CH}_{4}$ was produced by converting pure $\mathrm{CO}$ or synthetic CO-containing industrial waste gases at a high rate using a co-culture of T. onnurineus and M. villosus. These findings are a proof of principle and advance the fields of Archaea Biotechnology, artificial microbial ecosystem design and engineering, industrial waste-gas recycling, and biomethanation.
\end{abstract}

Keywords: Archaea Biotechnology; anaerobic microbiology; methanogenesis; biohydrogen; biological gas conversion

\section{Introduction}

In the European Union, around 70\% of primary energy is generated by the combustion of fossil fuels, contributing about $78 \%\left(3367 \mathrm{Tg}-\mathrm{CO}_{2}\right.$ equ.) of the total emitted greenhouse gases [1,2]. A transition to a carbon dioxide $\left(\mathrm{CO}_{2}\right)$-neutral and sustainable energy production system is urgently needed. One of the possibilities is to utilize the power-to-gas process [3-5]. Within this process, biomethanation of $\mathrm{CO}_{2}$ to methane $\left(\mathrm{CH}_{4}\right)$ offers a sustainable opportunity to enable the transition from fossil fuels, as it is an autobiocatalytic process. Therefore, it is envisioned that biomethanation will become an essential part of future energy production systems, as $\mathrm{CH}_{4}$ could be produced at a stable pace and stored in vast amounts in the natural gas grid network [6]. Pure cultures of methanogenic archaea (methanogens) [7-12] and enrichment cultures containing methanogens [13-17] can be utilized for in situ or ex situ biomethanation [18-20].

Carbon monoxide (CO)-containing rich waste gases are a by-product of industrial processes such as steelmaking [21]. CO-containing gases can also be obtained by gasification of carbon-rich materials, such as domestic organic waste or lignocellulose conversion to syngas [22]. The fact that biofuel production directly from lignocellulose is still costly and biotechnologically challenging makes microbial gas to gas conversion from $\mathrm{CO}$ a promising alternative bioprocess $[7,23]$. Developments in the transformation of gaseous waste products to energetically valuable compounds emphasize the potential for syngas as a substrate [24-27]. CO has a high potential for donating electrons, making it a favourable 
substrate for lithotrophic microorganisms [28,29]. Besides CO, waste and syngas mainly consist of molecular hydrogen $\left(\mathrm{H}_{2}\right), \mathrm{CO}_{2}$, and $\mathrm{CH}_{4}$. As early as 1990 , it was demonstrated that methanogens can metabolize some components from syngas [30].

The direct conversion of pure $\mathrm{CO}$ to $\mathrm{CH}_{4}$ was performed by hydrogenotrophic methanogens and subsequently analysed [31-34]. Furthermore, growth adaption to $\mathrm{CO}$ did not change the $\mathrm{CH}_{4}$ production rates significantly in the case of Methanothermobacter marburgensis, and the specific growth rate $(\mu)$ of Methanothermobacter thermautotrophicus on pure $\mathrm{CO}$ was only a hundredth of the growth rate achieved using $\mathrm{H}_{2}: \mathrm{CO}_{2}$ as a substrate [31]. This led to the assumption that an artificial co-culture, where $\mathrm{CO}$ is converted to $\mathrm{CH}_{4}$ in a successive bioprocess, would lead to higher efficiency, as microorganisms specifically adapted to the task of converting $\mathrm{CO}$ and producing $\mathrm{CH}_{4}$ can be selected. Studies showed that the independent performance of the water gas shift reaction (WGSR) and biomethanation by two different organisms in the same vessel resulted in a more than 20-fold faster conversion than direct conversion by a single organism [34]. Therefore, we hypothesized that an artificial co-culture of a carboxydotrophic, hydrogenogenic microbe with a hydrogenotrophic, autotrophic organism would drive favourable thermodynamic conditions for the WGSR. These conditions are created by direct removal of the gaseous metabolic end products of the WGSR, that is $\mathrm{H}_{2}: \mathrm{CO}_{2}$, by the methanogen. The conversions that are successively performed by the two organisms can be summarized with the following equation:

$$
4 \mathrm{CO}+4 \mathrm{H}_{2} \mathrm{O} \rightarrow 4 \mathrm{CO}_{2}+4 \mathrm{H}_{2} \rightarrow \mathrm{CH}_{4}+3 \mathrm{CO}_{2}+2 \mathrm{H}_{2} \mathrm{O}
$$

Overall, studies using a co-culture approach showed promising results for biomethane production rates [34,35]. Based on a previous study where a bacterial/archaeal co-culture was utilized [36], we wanted to investigate the potential of artificial archaeal co-cultures consisting of a carboxydotrophic, hydrogenogenic archaeon, and different hydrogenotrophic, autotrophic, and methanogenic archaea for biomethanation. We selected Thermococcus onnurineus for performing the catalysis of the WGSR, as it was shown that $\mu$ and $\mathrm{H}_{2}$ productivity on $\mathrm{CO}$ was substantially higher compared to other carboxydotrophic and hydrogenogenic microbes [37-40]. To catalyse the second part of the reaction, Methanocaldococcus jannaschii, Methanocaldococcus vulcanius, and Methanocaldococcus villosus were selected, because of their similar cultivation requirements to T. onnurineus with respect to temperature, salt concentration, and $\mathrm{pH}$ optimum. All four organisms were isolated from deep-sea hydrothermal vents and belong to the Euryarchaeota. They are able to grow in a temperature range of 63 to $86^{\circ} \mathrm{C}$, a salt concentration of 1 to $5 \%$, and a pH of 5.5 to 7.0 . T. onnurineus is a heterotroph, while the methanogens are chemolithoautotrophs [41-44]. Moreover, hyperthermophilic organisms are more advantageous over mesophiles, since at higher temperatures, a faster conversion of $\mathrm{CO}$ by the carboxydotrophic microorganism occurs, and a three times faster removal of $\mathrm{H}_{2}$ is obtained by the methanogen [34,45]. Therefore, the properties of a hyperthermophilic environment positively affects growth and conversion rates and is, thus, advantageous over mesophilic conditions. Here, we analysed whether T. onnurineus together with one of the three methanogens can be grown as a powerful artificial archaeal co-culture to efficiently generate biological $\mathrm{CH}_{4}$ from synthetic waste gases.

\section{Materials and Methods}

\subsection{Chemicals}

$\mathrm{CO}(99.999$ Vol.- $\%), \mathrm{H}_{2}: \mathrm{CO}(60 \mathrm{Vol} .-\%$ in $\mathrm{CO}), \mathrm{H}_{2}: \mathrm{CO}_{2}\left(80 \mathrm{Vol.}-\%\right.$ in $\left.\mathrm{CO}_{2}\right)$, and an artificial CO-containing syngas $\left(\mathrm{CO}_{2} 16.7\right.$ Vol.- $\%$, $\mathrm{H}_{2}$ Vol.- $\% 16.8 \%, \mathrm{CH}_{4}$ Vol.- $\% 14.7, \mathrm{~N}_{2}$ Vol.- $\%$ 14.5\%, and CO 37.3 Vol.- $\%$ ) were used for closed batch experiments. For gas chromatography (GC), $\mathrm{H}_{2}$ (99.999 Vol.- \%), $\mathrm{CO}_{2}$ (99.999 Vol.-\%), $\mathrm{CO}$ (99.999 Vol.-\%), $\mathrm{H}_{2} / \mathrm{CO}_{2}$ (80 Vol.- $\%$ in $\mathrm{CO}_{2}$ ), $\mathrm{H}_{2} / \mathrm{N}_{2}$ (4.5 Vol.- $\% \mathrm{H}_{2}$ in $\mathrm{N}_{2}$ ), $\mathrm{CH}_{4}$ (99.995 Vol.-\%), and the standard test gas (Messer $\mathrm{GmbH}$, Wien, Austria) (containing 0.01 Vol.- $\% \mathrm{CH}_{4}, 0.08$ Vol.- $\% \mathrm{CO}_{2}$ in $\mathrm{N}_{2}$ ) were used in addition to the gases mentioned above. All gases, except the standard 
test gas, were purchased from Air Liquide (Air Liquide GmbH, Schwechat, Austria). All other chemicals were of the highest grade available.

\subsection{Media}

Medium A is a modified version of the Deutsche Sammlung von Mikroorganismen und Zellkulturen (DSMZ) medium 282. The exact composition of medium A and medium B can be found in Supplementary Materials, Tables S1 and S2. Balch's vitamin solution was used [46]. For M. marburgensis and M. thermautotrophicus, a phosphate-buffered medium was used [47].

\subsection{Strains and Cultivation Conditions}

The strains M. jannaschii JAL-1, M. villosus KIN24-T80, M. vulcanius M7, M. marburgensis DSM 2133 (Marburg), and M. thermautotrophicus DSM 1053 (delta H) were purchased from the DSMZ. T. onnurineus NA1 was provided by Prof. Dr. Sung Gyun Kang (Korea Institute of Ocean Science and Technology (KIOST), Ansan, Korea).

Every cultivation was performed in closed batch mode [48]. Experiments were conducted in $120 \mathrm{~mL}$ serum bottles (Ochs Glasgeraetebau, Langerwehe, Germany), sealed with a $20 \mathrm{~mm}$ butyl rubber stopper and an aluminium crimp cap (Chemglass Life Science LLC, Vineland, NJ, USA). Serum bottles were filled with the corresponding medium and sealed. Anaerobic conditions were created by evacuating and re-pressurizing with $\mathrm{H}_{2}: \mathrm{CO}_{2}$ (4:1) to 0.5 barg five times. The bottles were autoclaved and stored at $4{ }^{\circ} \mathrm{C}$ until further use. Unless otherwise stated, the medium was augmented with the following sterile filtered stock solutions before inoculation: $\mathrm{NaHCO}_{3}$, L-Cysteine-HCL, and Balch's Vitamin solution [46] (see Supplementary Materials, Tables S1 and S2). Afterwards, the bottles were flushed with $\mathrm{H}_{2}: \mathrm{CO}_{2}$ (4:1) to 0.5 barg, before the addition of autoclaved $\mathrm{Na}_{2} \mathrm{~S} \cdot 9 \mathrm{H}_{2} \mathrm{O}$.

The inoculum, $1 \mathrm{~mL}(2 \% \mathrm{v} / \mathrm{v})$ of an actively grown culture, was added anaerobically. The final liquid phase in each serum bottle added up to $50 \mathrm{~mL}$. Depending on the experiment, the headspace gas phase was exchanged with the corresponding gas. Bottles were incubated at $80^{\circ} \mathrm{C}$ in either a double-layer shaking incubator at $100 \mathrm{rpm}$ (LABWIT ZWYR-2102C, Labwit Scientific Pty Ltd., Burwood East, Australia) or in a water bath at 100 lateral shakes per minute (GFL 1083, LAUDA-GFL, Burgwedel, Germany).

\subsection{Pure-Culture Closed Batch Experiments}

The methanogens $M$. villosus, $M$. vulcanius, and $M$. jannaschii were grown under 2 barg $\mathrm{H}_{2}: \mathrm{CO}_{2}$ in either medium A or $\mathrm{B}$. A reduced version of them without vitamins, yeast extract, trace elements, or a combination of the three was also tested. The incubation rhythm consisted of 13 and $7 \mathrm{~h}$ incubation periods, with $2 \mathrm{~h}$ of sampling in between every period. The same rhythm was applied for cultivation of T. onnurineus. It was grown in the same medium, but under 1 barg CO. These incubation periods did not apply for M. marburgensis and M. thermautotrophicus, because of their slow growth. Furthermore, they were grown in a phosphate-buffered M. marburgensis medium with either 1.7 barg $\mathrm{CO}, 1.7$ barg $\mathrm{H}_{2}: \mathrm{CO}(4: 1)$, or $1.7 \mathrm{H}_{2}: \mathrm{CO}_{2}(4: 1)$.

\subsection{Co-Culture Closed Batch Experiments}

The co-cultures consisted of T. onnurineus and either M. villosus, M. vulcanius, or M. jannaschii. The experiments were conducted according to two general schemes. In the first setup, the experiment started by growing the respective Methanocaldococcus strain under 2 barg $\mathrm{H}_{2}: \mathrm{CO}_{2}$ first. After $13 \mathrm{~h}$ in the incubator, T. onnurineus was added. The bottles were then pressurized with $\mathrm{CO}, \mathrm{H}_{2}: \mathrm{CO}$, or artificial syngas to $1 \mathrm{barg}$. In the second setup, T. onnurineus grew $13 \mathrm{~h}$ under pure $\mathrm{CO}, \mathrm{H}_{2}: \mathrm{CO}$, or artificial syngas before one of the Methanocaldococcus strains was added. From this point onward, both schemes followed the same incubation rhythm, as described in the pure-culture experiments, and ended after a maximum of $80 \mathrm{~h}$ of cumulative incubation time. Every experiment was performed in hexuplicates $(n=6)$ on media A and B, as well as on reduced versions of them. 


\subsection{Sampling}

The routinely performed sampling consisted of removing the cultures from the incubator and measuring the pressure as soon as the bottles cooled down to room temperature ( $\sim 60 \mathrm{~min}$ ). To analyse growth, $0.7 \mathrm{~mL}$ of the cultures were withdrawn for optical density (OD) measurements $(\lambda=578 \mathrm{~nm})$. Lastly, the bottles were flushed and re-pressurized with the corresponding gas.

\subsection{Analytical Procedures}

OD of the cultures was measured via a spectrophotometer at $\lambda=578 \mathrm{~nm}$ (Specord 200 Plus, Analytik Jena, Jena, Germany). The headspace gas composition before and after inoculation in pure cultures was determined via the gas headspace pressure difference $[18,47,49]$. Gas evolution and uptake rates were calculated according to methods described in refs. $[47,50,51]$. Samples that were withdrawn for gas chromatography (GC) analysis did not undergo the sampling procedure. The headspace gas composition in co-culture experiments was analysed via GC, and the evolution and uptake rates were calculated [52]. Some of the negative controls revealed "air contamination" and were removed from the calculations of the results. To maintain the correct atmosphere, OD was measured after completion of the GC run and as such is only an estimate of the true OD.

\section{Results}

\subsection{Growth Kinetics of Methanogens in Defined Medium}

Growth and gas conversion by the methanogens $M$. villosus, $M$. vulcanius, and $M$. jannaschii were analysed in defined versions of media $\mathrm{A}$ and $\mathrm{B}$ on $\mathrm{H}_{2}: \mathrm{CO}_{2}$ (4:1), by removing complex components. Removal of the trace elements from the media hindered growth. $M$. villosus showed a higher methane evolution rate (MER) than the other two methanogens in medium A and B (Figure 1).

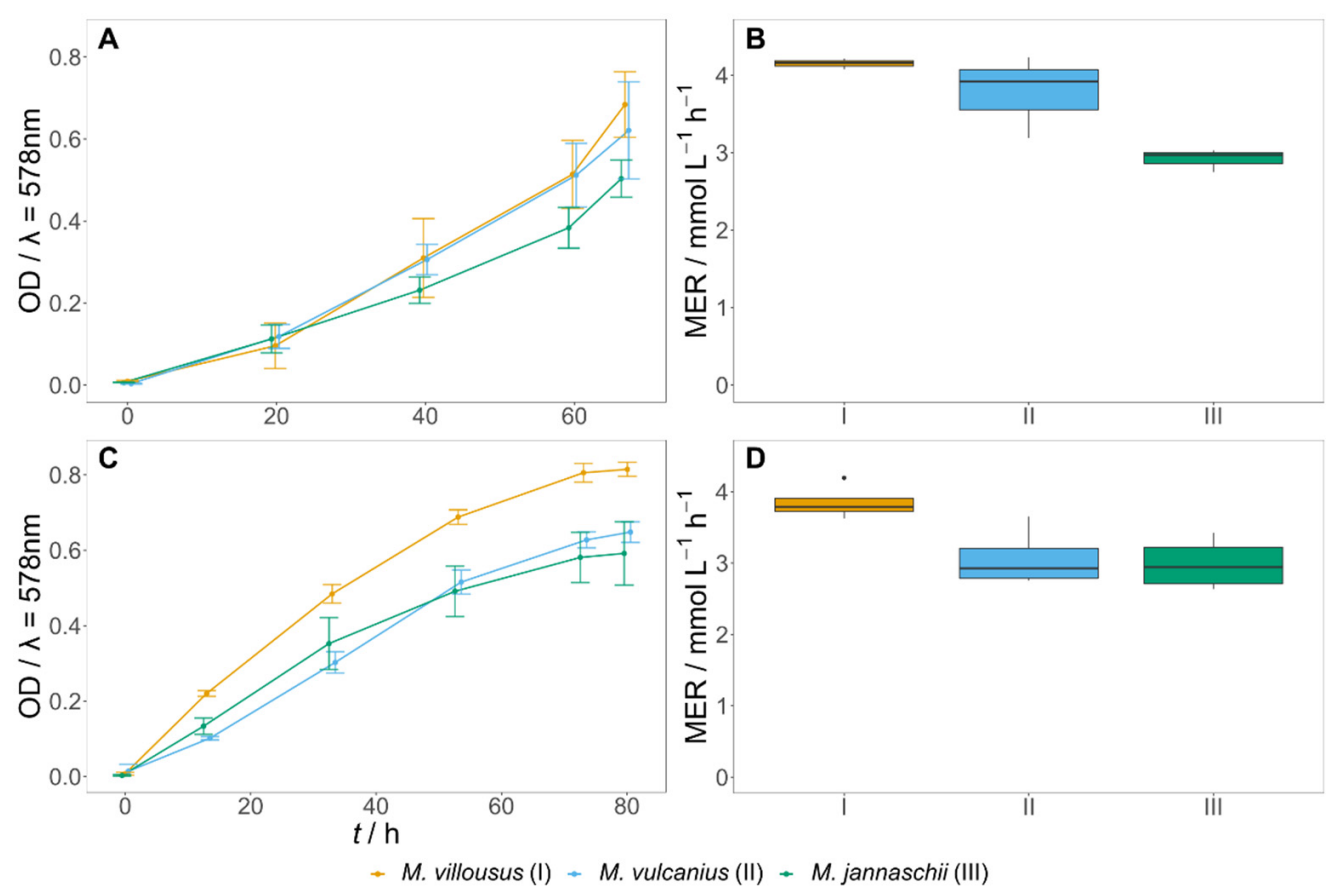

Figure 1. Growth kinetics and MER of M. villosus, M. vulcanius, and M. jannaschii. (A,B) grown in medium A; (C,D) grown in medium B. Both media were without yeast extract and vitamins. Error bars in the line graphs show the standard deviation. All experiments are $N=1, n=3$. However, $\mathrm{N}=2, \mathrm{n}=3$ for $M$. villosus using medium $\mathrm{B}$. 
M. marburgensis and $M$. thermautotrophicus were grown on $\mathrm{CO}, \mathrm{H}_{2}: \mathrm{CO}(3: 1)$ and $\mathrm{H}_{2}: \mathrm{CO}_{2}$ (4:1) [53]. The analysis showed that $M$. marburgensis and $M$. thermautotrophicus, when grown on $\mathrm{H}_{2}: \mathrm{CO}_{2}(4: 1)$, had a high turnover, and furthermore, experiments on $\mathrm{H}_{2}: \mathrm{CO}$ resulted in poor $\mathrm{CH}_{4}$ conversion. No growth was observed on pure CO (see Supplementary Materials, Figure S1, Table S5). Due to these findings, M. marburgensis and M. thermautotrophicus were excluded from the co-culture experiments.

\subsection{T. onnurineus Grown on $\mathrm{CO}$}

T. onnurineus was grown individually in a pure culture in media A and B. Results indicated that the organism reached higher $\mathrm{OD}_{578}$ when grown on medium $\mathrm{A}$ as well as achieved a higher gas conversion than in media B. Omission of vitamins from medium B showed no difference regarding the $\mathrm{H}_{2}$ evolution rate (HER) (see Supplementary Materials, Table S6, Figure S2).

\subsection{Artificial Archaeal Co-Culture Engineering}

Conversion of $\mathrm{CO}$ to $\mathrm{CH}_{4}$ and $\mathrm{CO}_{2}$ was performed with a co-culture consisting of T. onnurineus together with either $M$. villosus, M. jannaschii, or M. vulcanius. After pregrowth of the methanogens for $13 \mathrm{~h}$, the cultures were inoculated with T. onnurineus. Growth and gas rates were analysed for all three co-cultures in media A and B (Tables 1 and 2, Figure 2). Co-cultures in medium $A$ had relatively similar MERs ranging from 1.4 to $1.6 \mathrm{mmol} \mathrm{L}^{-1} \mathrm{~h}^{-1}$, whereas in medium $\mathrm{B}$, the co-culture consisting of $M$. villosus and T. onnurineus achieved MERs between 1.6 and $2.0 \mathrm{mmol} \mathrm{L}^{-1} \mathrm{~h}^{-1}$. In general, the measured mean gas evolution and uptake rates were either equal or slightly higher in medium $\mathrm{B}$. The higher $\mathrm{CO}$ uptake rate (COUR) and $\mathrm{CO}_{2}$ evolution rate (CER) in medium $\mathrm{B}$ indicated that $T$. onnurineus performed better under this condition. It is likely that the $\mathrm{H}_{2}$ uptake rate (HUR) of the methanogens positively influenced the COUR of T. onnurineus by creating favourable thermodynamic conditions [34].

Table 1. Mean gas evolution and uptake rates of the co-cultures cultivated in medium A on $100 \% \mathrm{CO}^{1}$.

\begin{tabular}{|c|c|c|c|c|c|}
\hline Co-Culture & $\mathrm{MER} / \mathrm{mmol} \mathrm{L}^{-1} \mathrm{~h}^{-1}$ & HUR/mmol L ${ }^{-1} h^{-1}$ & $\mathrm{CUR} / \mathrm{mmol} \mathrm{L}^{-1} \mathrm{~h}^{-1}$ & COUR/mmol L $\mathrm{L}^{-1} \mathrm{~h}^{-1}$ & $\mathrm{CER} / \mathrm{mmol} \mathrm{L}^{-1} \mathrm{~h}^{-1}$ \\
\hline M. villosus + T. onnurineus & $1.4 \pm 0.4$ & $6.4 \pm 1.5$ & $1.4 \pm 0.4$ & $6.4 \pm 1.5$ & $5.0 \pm 1.1$ \\
\hline M. vulcanius + T. onnurineus & $1.6 \pm 0.3$ & $7.0 \pm 1.3$ & $1.6 \pm 0.3$ & $7.0 \pm 1.3$ & $5.4 \pm 0.9$ \\
\hline M. jannaschii + T. onnurineus & $1.5 \pm 0.4$ & $6.5 \pm 1.5$ & $1.5 \pm 0.3$ & $6.5 \pm 1.5$ & $5.0 \pm 1.2$ \\
\hline
\end{tabular}

${ }^{1}$ Measurements were taken after a $7 \mathrm{~h}$ incubation period. Data collected at indicated timepoints in Figure $2 \mathrm{~A}$. $(\mathrm{N}=1, \mathrm{n}=6)$. Values are shown with standard deviation.

Table 2. Mean gas evolution and uptake rates of the co-cultures cultivated in medium $\mathrm{B}$ on $100 \% \mathrm{CO}^{1}$.

\begin{tabular}{|c|c|c|c|c|c|}
\hline Co-Culture & $\mathrm{MER} / \mathrm{mmol} \mathrm{L}^{-1} \mathrm{~h}^{-1}$ & HUR/mmol L ${ }^{-1} h^{-1}$ & $\mathrm{CUR} / \mathrm{mmol} \mathrm{L}^{-1} \mathrm{~h}^{-1}$ & COUR/mmol L-1 $\mathrm{h}^{-1}$ & $\mathrm{CER} / \mathrm{mmol} \mathrm{L}^{-1} \mathrm{~h}^{-1}$ \\
\hline M. villosus + T. onnurineus & $2.0 \pm 0.3$ & $8.3 \pm 1.3$ & $2.1 \pm 0.3$ & $8.4 \pm 1.3$ & $6.3 \pm 0.9$ \\
\hline M. vulcanius $+T$. onnurineus & $1.6 \pm 0.5$ & $10.3 \pm 0.2$ & $2.6 \pm 0.3$ & $11.3 \pm 0.7$ & $8.7 \pm 0.5$ \\
\hline M. jannaschii + T. onnurineus & $1.8 \pm 0.4$ & $9.0 \pm 1.5$ & $1.9 \pm 0.5$ & $9.1 \pm 1.6$ & $7.2 \pm 1.2$ \\
\hline
\end{tabular}

${ }^{1}$ Measurements were taken after a $7 \mathrm{~h}$ incubation period. Data collected at indicated timepoints in Figure $2 \mathrm{~B}$. $(\mathrm{N}=1, \mathrm{n}=6)$. Values are shown with standard deviation.

The results suggested that the co-culture with $M$. vulcanius was less efficient in medium $\mathrm{B}$, as it had a higher $\mathrm{CO}_{2}$ uptake rate (CUR) and HUR, compared to medium A, but not a higher MER. This agrees with the results obtained from pure-culture experiments, where medium B led to a slightly lower MER of M. vulcanius compared to the other methanogens.

Comparison of the MERs between the pure and the co-cultures suggested that, on average, a lower MER was measured in the co-cultures (Tables 1 and 2, Figure 1). A likely reason for this was that they were dependent on the conversion of $\mathrm{CO}$ to $\mathrm{CO}_{2}$ and $\mathrm{H}_{2}$ by T. onnurineus. Figure 3 shows that the $\mathrm{CH}_{4}$ production and growth occurred at the highest capacity, as the $\mathrm{H}_{2}$ content in most cultures was below $1 \mathrm{~mol} \%$, except for one case, suggesting it was fully converted. As such, the rate-limiting step in $\mathrm{CH}_{4}$ production by the methanogens in the co-culture was the availability of $\mathrm{H}_{2}$. 


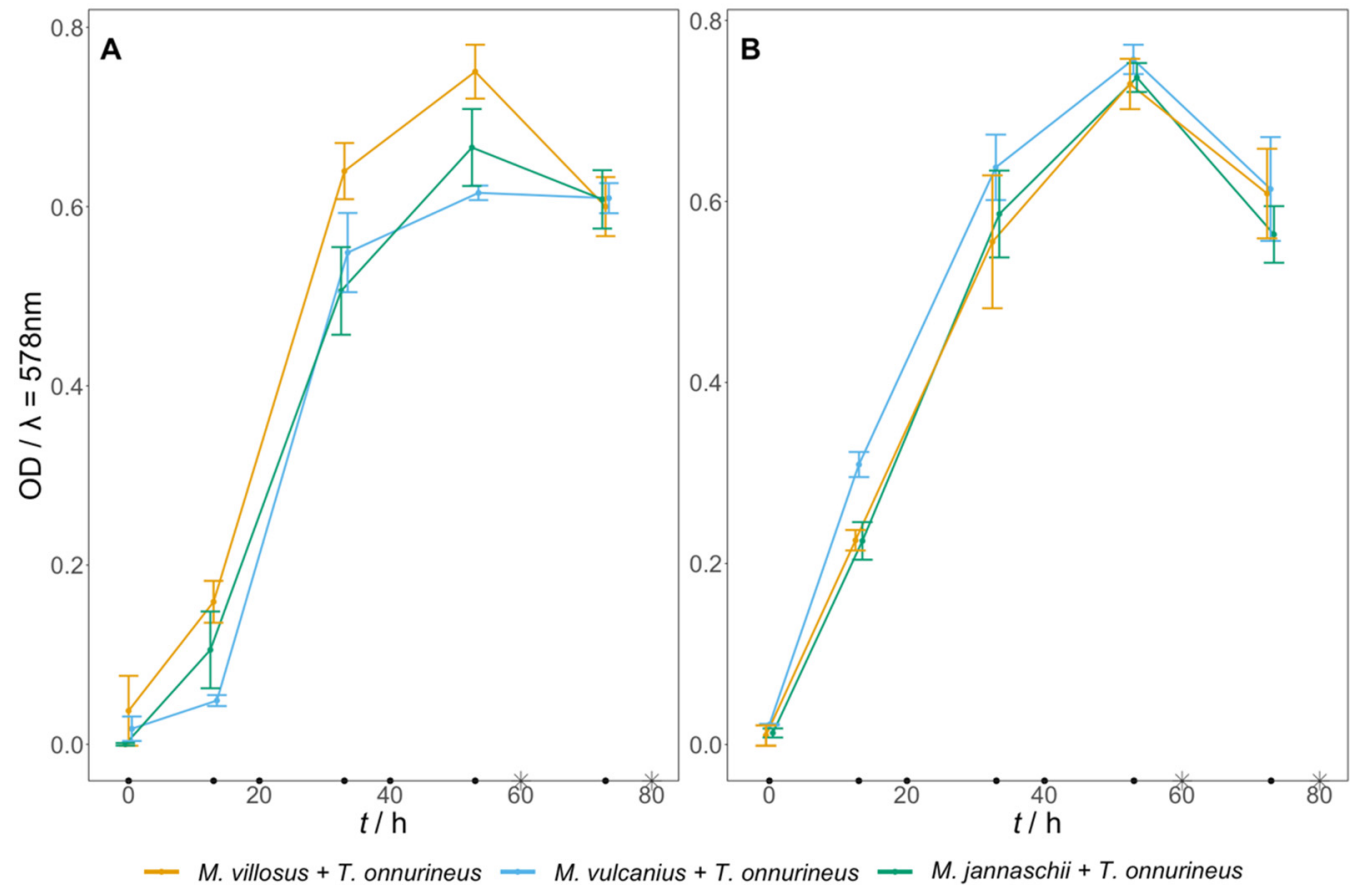

Figure 2. Growth kinetics of either M. villosus, M. jannaschii, or M. vulcanius with T. onnurineus. After the first $13 \mathrm{~h}$, the medium was inoculated with T. onnurineus and the gas phase was exchanged from $\mathrm{H}_{2}: \mathrm{CO}_{2}$ to $\mathrm{CO}$. The error bars show the standard deviation. Closed black circles on the $x$-axis mark the re-pressurising of the headspace with $\mathrm{CO}$. The asterisks on the $x$-axis indicate the sampling points for GC analysis. (A) Growth in medium A; (B) growth in medium B. N=1, $\mathrm{n}=6$.

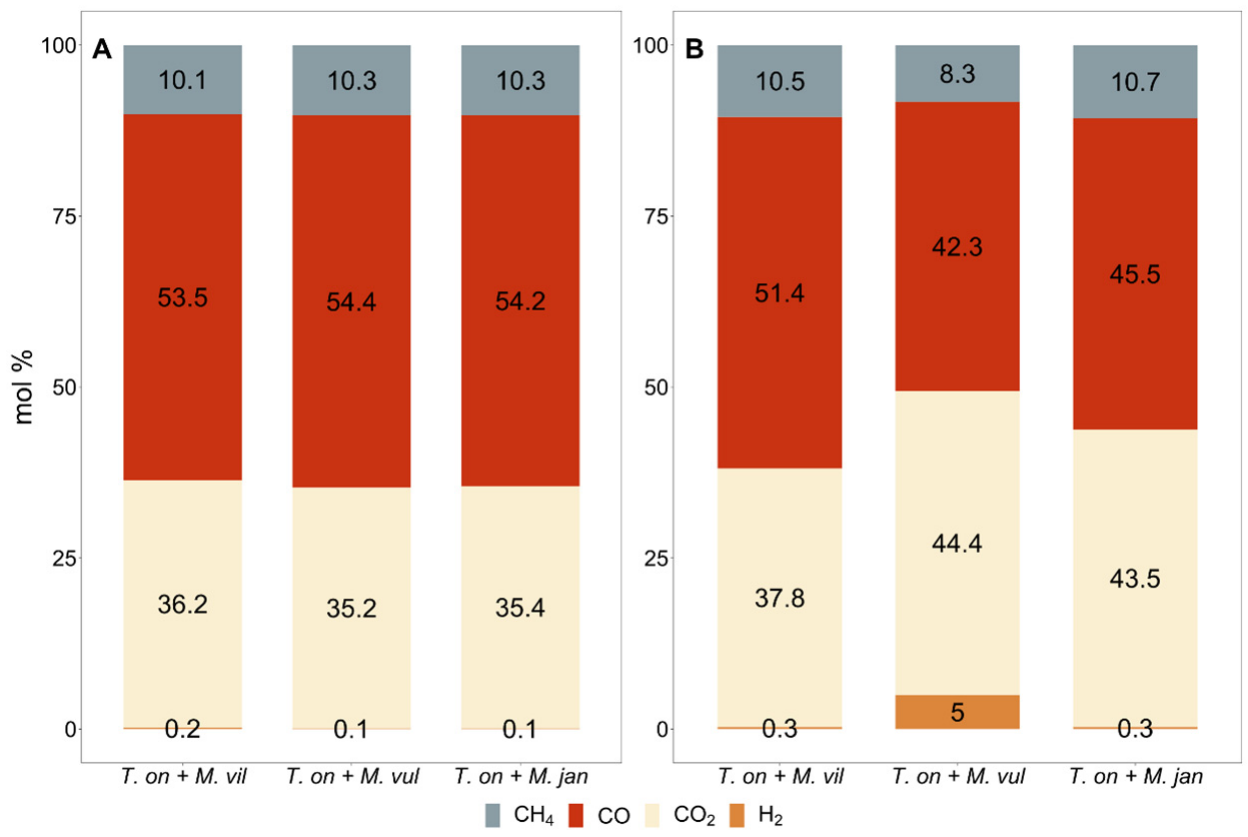

Figure 3. Relative mean molar gas composition in the co-cultures headspace after a $7 \mathrm{~h}$ incubation period on CO. Measurements were taken at the timepoints indicated in Figure 2. (A) Co-culture cultivated in medium A; (B) co-culture cultivated in medium B. $\mathrm{N}=1, \mathrm{n}=6$.

To circumvent $\mathrm{H}_{2}$ limitation in the co-culture experiments, two strategies were employed. First, to create a functional culture with a high $\mathrm{H}_{2}$ production rate in advance of the methanogen being added, an inoculation scheme was tested, where T. onnurineus was initially grown $13 \mathrm{~h}$ on $\mathrm{CO}$, prior to addition of said methanogen. Second, a different gas 
composition, $\mathrm{H}_{2}$ : $\mathrm{CO}(3: 1)$ instead of pure $\mathrm{CO}$, was used to provide additional $\mathrm{H}_{2}$ available in the atmosphere. In addition, an experiment with a gas composition resembling that of industrial waste or syngases was performed [21]. The co-cultures were exposed to an artificial syngas (see Section 2.1) that could arise by industrial processes (Table 3). As T. onnurineus grown with $M$. villosus in medium B was considered the best co-culture, this pair was used. However, it should be noted that these were closed batch experiments and that the productivities are dependent on the conversion kinetics and on the tested time interval.

Table 3. Mean gas evolution rates of co-cultures in medium B under different gas compositions and inoculation orders ${ }^{1}$.

\begin{tabular}{|c|c|c|c|}
\hline Co-Culture & Gas & $\mathrm{MER} / \mathrm{mmol} \mathrm{L}^{-1} \mathrm{~h}^{-1}$ & $\mathrm{CER} / \mathrm{mmol} \mathrm{L}^{-1} \mathrm{~h}^{-1}$ \\
\hline M. villosus + T. onnurineus & $\mathrm{CO}$ & $2.0 \pm 0.3$ & $6.3 \pm 0.9$ \\
\hline T. onnurineus $+M$. villosus & $\mathrm{CO}$ & $1.1 \pm 0.1$ & $3.7 \pm 1.0$ \\
\hline M. villosus $+T$. onnurineus & $\mathrm{H}_{2}: \mathrm{CO}$ & $1.0 \pm 0.4$ & $0.0 \pm 0.0$ \\
\hline T. onnurineus + M. villosus & $\mathrm{H}_{2}: \mathrm{CO}$ & $1.0 \pm 0.3$ & $0.0 \pm 0.0$ \\
\hline M. villosus $+T$. onnurineus & Art. syngas & $1.5 \pm 0.5$ & $0.9 \pm 0.6$ \\
\hline T. onnurineus + M. villosus & Art. syngas & $0.9 \pm 0.3$ & NA \\
\hline
\end{tabular}

${ }^{1}$ Measurements were taken after a $7 \mathrm{~h}$ incubation period $(\mathrm{N}=1, \mathrm{n}=6)$. Values are shown with standard deviation.

In experiments with pure CO, the MER was twice as high when M. villosus was added first. The average $\mathrm{H}_{2}$ content turned out to remain below $0.3 \mathrm{~mol} \%$ (see Supplementary Materials, Table S7). When gassing with $\mathrm{H}_{2}: \mathrm{CO}$, interestingly, both inoculation schemes showed a decreasing performance over time, as revealed by a MER, which was only half of what was achieved when pure $\mathrm{CO}$ was used (Table 3). However, the measured $\mathrm{CO}_{2}$ levels were below $0.1 \mathrm{~mol} \%$ in both cases (see Supplementary Materials, Table S7). This could have been caused by the presence of $\mathrm{H}_{2}$ in the $\mathrm{H}_{2}: \mathrm{CO}$, as the additional application of $\mathrm{H}_{2}$ within the gas negatively affected growth and performance of T. onnurineus, which in turn most likely hindered the MER. The reduced CER by T. onnurineus may have been caused by the lower partial pressure of $\mathrm{CO}$ in the serum bottle headspace.

In the experiment where the artificial syngas mix was used and where M. villosus was pre-grown, the MER was $1.5 \pm 0.5 \mathrm{mmol} \mathrm{L}{ }^{-1} \mathrm{~h}^{-1}$. The average $\mathrm{CH}_{4} \mathrm{~mol} \%$ increased by about $10 \%$ to $24.8 \mathrm{~mol} \%$. This increase was similar to what was obtained when using pure $\mathrm{CO}$, although the MER decreased as the experiment progressed. We did not observe a negative impact on the MER during co-culture experiments when elemental sulphur was added.

\section{Discussion}

This study is a new brick in the emerging research field of Archaea Biotechnology [54] and artificial microbial ecosystem design and engineering [55]. We investigated the conversion of one-carbon substrates $\left(\mathrm{CO}, \mathrm{H}_{2}: \mathrm{CO}\right.$, and $\mathrm{CO}$-rich waste gases) by the artificially designed co-cultures of either $M$. villosus, M. jannaschii, or M. vulcanius together with T. onnurineus. Our results showed fast and reliable gas conversion, with a reduction in pure $\mathrm{CO}$ to about $50 \mathrm{~mol} \%$ and simultaneous production of $\sim 10 \mathrm{~mol} \% \mathrm{CH}_{4}$ within $7 \mathrm{~h}$. The most efficient conversion of the artificial syngas was performed by the co-culture $M$. villosus with T. onnurineus, inoculated in this order. This culture showed a CO reduction of $7 \%$, starting from $37.3 \mathrm{~mol} \%$ and an increase in $\mathrm{CH}_{4}$ by $\sim 10 \mathrm{~mol} \%$ within $7 \mathrm{~h}$. This proved the ability of the co-cultures to convert a variety of different $\mathrm{CO}$-containing gas compositions with a lower proportion of $\mathrm{CO}$. 
A study with a similar experimental setup reported an $\sim 6 \% \mathrm{CH}_{4}$ increase after $22 \mathrm{~h}$ [35]. We obtained $10 \%$ increase in $7 \mathrm{~h}$. This suggests that the established co-culture (T. onnurineus / M. villosus) is of higher catalytic power. Nonetheless, most up-to-date published co-cultures were tested in different setups than the one reported in this study, making a direct comparison of evolution and uptake rates rather difficult [26,30,34]. Establishing different co-cultures in a bioreactor setup will, thus, be of great importance to fully understand their growth and production kinetics.

Pure-culture closed batch experiments of the methanogens in a defined medium on $\mathrm{H}_{2}: \mathrm{CO}_{2}$ showed a higher MER $\left(4.2 \pm 0.1 \mathrm{mmol} \mathrm{L}^{-1} \mathrm{~h}^{-1}\right)$ than the co-cultures $\left(2.0 \pm 0.3 \mathrm{mmol} \mathrm{L}^{-1} \mathrm{~h}^{-1}\right)$ (Figure 1, Table 3). Therefore, the potential for achieving a higher MER in co-cultures is possible if the necessary gas supply can be performed, and the inhibitory concentration of $\mathrm{CO}$ would not be surpassed [56]. Although the main limitation of the co-culture grown on pure $\mathrm{CO}$ was the availability of $\mathrm{H}_{2}$ for methanogenesis and, hence, the conversions of $\mathrm{CO}$ to $\mathrm{H}_{2}$ and $\mathrm{CO}_{2}$ by T. onnurineus (Figure 3 and Supplementary Materials, Table S7). The addition of $\mathrm{H}_{2}$ to the gas phase did not provide an increase in the MER. Rather, it led to a limitation of $\mathrm{CO}_{2}$ availability (Supplementary Materials, Table S7), most likely due to the reduced performance of T. onnurineus under the lower $\mathrm{CO}$ partial pressure. Consequently, application of the artificial syngas led to an increase in MER, as biomethanation seems to be neither limited by $\mathrm{CO}_{2}$ nor $\mathrm{H}_{2}$ availability. Nonetheless, it did not reach the same values as in pure $\mathrm{CO}$ (Table 3). This can be explained by the concentration reduction in $\mathrm{CO}, \mathrm{CO}_{2}$, and $\mathrm{H}_{2}$ in syngas by the other initially present gases, reducing substrate availability.

A change in the cultivation method to a bioreactor setup with higher pressure, agitation, and a constant gassing, resulting in having a higher gas solubility and higher gas transfer rate to the liquid phase, might increase the conversion of $\mathrm{CO}$ by T. onnurineus and the potential of the co-culture $[37,39,48]$. However, the ratio of the gas in the liquid phase has to be considered carefully, as high agitation might also lead to an excessive CO availability for the methanogens [34]. As recently more and more genetic tools for archaea become available, an overexpression of the carbon monoxide dehydrogenase could also be a solution to debottleneck CO conversion by T. onnurineus [39,57].

Unfortunately, T. onnurineus is still dependent on a complex medium containing yeast extract, which limits the potential industrial applicability. However, co-cultivation could be used to gain advantages or improve growth of both microorganisms through improving their syntrophic relationships [34]. Finding a suitable defined medium for $T$. onnurineus or replacing it by a different organism that can catalyse the WGSR from CO in minimal conditions is one suggested avenue of research. Carboxydocella thermautotrophica or Carboxydocella sporoproducens would fall into the same $\mathrm{pH}$ and temperature conditions as the herein employed methanogens [35].

A direct conversion of $\mathrm{CO}$ to $\mathrm{CH}_{4}$ by a single organism such as $\mathrm{M}$. marburgensis or M. thermautotrophicus is likely not the most suitable biotechnological approach, as the inhibitory concentration of $\mathrm{CO}$ for these methanogens is very low [31,34]. The artificially created archaeal co-cultures consisting of one of the hyperthermophilic methanogenic archaea M. villosus, M. jannaschii, and M. vulcanius together with T. onnurineus, as performed in this study, are highly efficient and reliable for biomethanation. By adaptation to a minimal medium and by performing targeted bioprocess development, artificial archaeal co-cultures could be of environmental, economic, and industrial value in renewable energy production and storage.

\section{Conclusions}

This contribution is another step in the rapidly developing research field of Archaea Biotechnology. Furthermore, it is a proof of principle for the design and engineering of artificial microbial co-cultures. Additionally, it marks a cornerstone in the use of artificial archaeal co-cultures for the biomethanation of syngas. This design of artificial archaeal co-cultures represents a novelty in the field of biomethanation, due the unique selection of 
organisms and their hyperthermophilic growth conditions. The created co-cultures convert a variety of different $\mathrm{CO}$-containing gases, including syngas, to $\mathrm{CH}_{4}$. As the WGSR might still be the limiting factor, finding the best organism for conversion of $\mathrm{H}_{2} \mathrm{O}: \mathrm{CO}$ to $\mathrm{H}_{2}: \mathrm{CO}_{2}$ will be of future relevance to enhance the kinetics of the artificial co-culture. Apart from the choice of the archaea, the inoculation sequence of the strains and medium development are crucial factors for a successful design. These factors will be important in engineering the next steps for scaling up the bioprocess of artificial archaeal co-cultures. Inferring from our results, hyperthermophilic and anaerobic archaea are of great biotechnological relevance, as they act as highly efficient $\mathrm{H}_{2}$ and $\mathrm{CH}_{4}$ cell factories in artificial co-culture.

Supplementary Materials: The following are available online at https:/ /www.mdpi.com/article/10.3390/ fermentation7040276/s1, Table S1: Chemical composition of medium A, Table S2: Chemical composition of medium B, Table S3: 141 trace element solution modified from DSMZ, Table S4: Holden's trace element solution 2, Table S5: The physiological maximal and mean values of $\mathrm{CH}_{4}$ production and growth kinetics of M. marburgensis and M. thermautotrophicus, Table S6: HER of T. onnurineus after $7 \mathrm{~h}$ of incubation, Table S7: Relative mean molar gas composition of the co-culture's headspace after a $7 \mathrm{~h}$ incubation period, Figure S1: Growth of M. marburgensis and M. thermautotrophicus in defined medium, Figure S2: Growth of T. onnurineus at 1 barg CO.

Author Contributions: Conceptualization, A.Z., T.S. and S.K.-M.R.R.; methodology, B.R., I.K., M.V. and S.K.-M.R.R.; validation, A.Z., B.R. and S.K.-M.R.R.; formal analysis, A.Z.; investigation, A.Z., B.R., T.S., M.S. and C.P.; resources, M.V. and S.K.-M.R.R.; data curation, A.Z. and B.R.; writing-original draft preparation, A.Z., B.R. and S.K.-M.R.R.; writing-review and editing, A.Z., B.R., I.K., M.V. and S.K.-M.R.R.; visualization, A.Z.; supervision, S.K.-M.R.R.; project administration, M.V. and S.K.-M.R.R.; funding acquisition, M.V. and S.K.-M.R.R. All authors have read and agreed to the published version of the manuscript.

Funding: Greatly acknowledged is the Österreichische Forschungsförderungsgesellschaft (FFG) for funding the project BioHyMe (grant no. 853615). The BMBWF is acknowledged for supporting the research with the WTZ project CZ 08/2020. Open access funding by the University of Vienna.

Institutional Review Board Statement: Not applicable.

Informed Consent Statement: Not applicable.

Data Availability Statement: The datasets used and/or analysed during the current study are available from the corresponding author on reasonable request.

Acknowledgments: S.K.-M.R.R. greatly acknowledges Sung Gyun Kang (Korea Institute of Ocean Science and Technology (KIOST), Ansan, Reublic of Korea) for providing T. onnurineus NA1. We want to thank Angus Hilts for comments on and proofreading of the manuscript.

Conflicts of Interest: B.R. and S.K.-M.R.R. declare competing interests due to their employment in the Arkeon $\mathrm{GmbH}$. All other authors declare no competing interest.

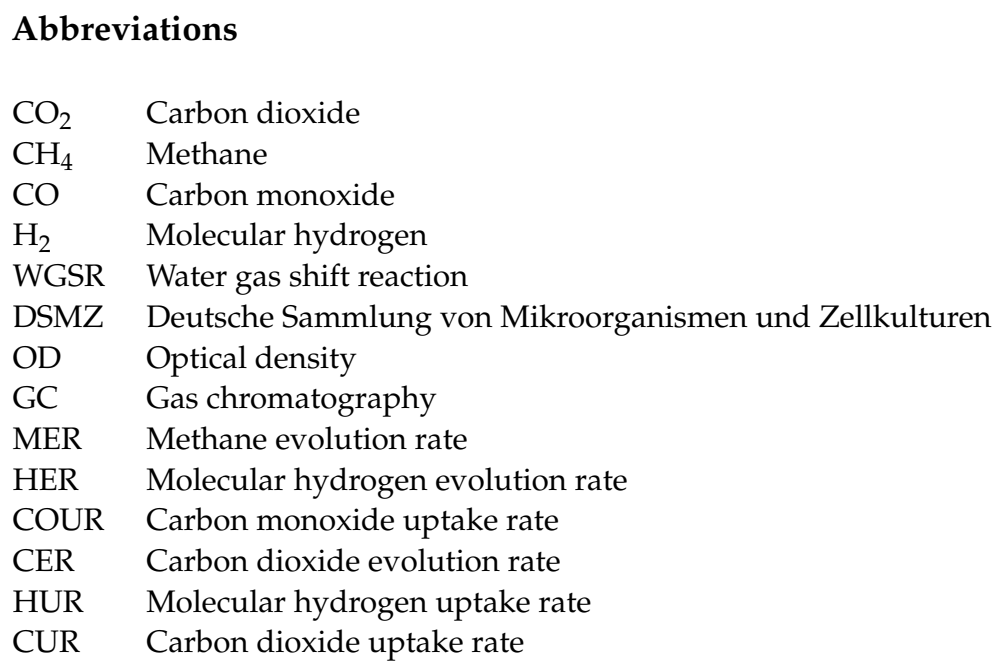




\section{References}

1. EEA (European Environment Agency). Primary Energy Consumption by Fuel in the EU-27; EEA: København, Denmark, 2020; Volume 28.

2. EEA (European Environment Agency). National Emissions Reported to the UNFCCC and to the EU Greenhouse Gas Monitoring Mechanism; EEA: København, Denmark, 2019; Available online: https://www.eea.europa.eu/data-and-maps/data/nationalemissions-reported-to-the-unfccc-and-to-the-eu-greenhouse-gas-monitoring-mechanism-14 (accessed on 10 November 2021).

3. Sterner, M.; Specht, M. Power-to-Gas and Power-to-X-The History and Results of Developing a New Storage Concept. Energies 2021, 14, 6594. [CrossRef]

4. Götz, M.; Lefebvre, J.; Mörs, F.; McDaniel Koch, A.; Graf, F.; Bajohr, S.; Reimert, R.; Kolb, T. Renewable Power-to-Gas: A Technological and Economic Review. Renew. Energy 2016, 85, 1371-1390. [CrossRef]

5. Rönsch, S.; Schneider, J.; Matthischke, S.; Schlüter, M.; Götz, M.; Lefebvre, J.; Prabhakaran, P.; Bajohr, S. Review on Methanation From Fundamentals to Current Projects. Fuel 2016, 166, 276-296. [CrossRef]

6. Eyl-Mazzega, M.-A.; Mathieu, C.; Boesgaard, K.; Daniel-Gromke, J.; Denysenko, V.; Liebetrau, J.; Cornot-Gandolphe, S. Biogas and Bio-Methane in Europe: Lessons from Denmark, Germany and Italy; Études de l'Ifri; French Institute of International Relations (IFRI): Paris, France, 2019; ISBN 979-10-373-0025-6.

7. Rittmann, S.K.-M.; Seifert, A.H.; Bernacchi, S. Kinetics, Multivariate Statistical Modelling, and Physiology of CO2-Based Biological Methane Production. Appl. Energy 2018, 216, 751-760. [CrossRef]

8. Mauerhofer, L.-M.; Zwirtmayr, S.; Pappenreiter, P.; Bernacchi, S.; Seifert, A.H.; Reischl, B.; Schmider, T.; Taubner, R.-S.; Paulik, C.; Rittmann, S.K.-M.R. Hyperthermophilic Methanogenic Archaea Act as High-Pressure CH4 Cell Factories. Commun. Biol. 2021, 4, 289. [CrossRef]

9. Mauerhofer, L.-M.; Reischl, B.; Schmider, T.; Schupp, B.; Nagy, K.; Pappenreiter, P.; Zwirtmayr, S.; Schuster, B.; Bernacchi, S.; Seifert, A.H.; et al. Physiology and Methane Productivity of Methanobacterium Thermaggregans. Appl. Microbiol. Biotechnol. 2018, 102, 7643-7656. [CrossRef] [PubMed]

10. Abdel Azim, A.; Pruckner, C.; Kolar, P.; Taubner, R.-S.; Fino, D.; Saracco, G.; Sousa, F.L.; Rittmann, S.K.-M.R. The Physiology of Trace Elements in Biological Methane Production. Bioresour. Technol. 2017, 241, 775-786. [CrossRef]

11. Seifert, A.H.; Rittmann, S.; Herwig, C. Analysis of Process Related Factors to Increase Volumetric Productivity and Quality of Biomethane with Methanothermobacter Marburgensis. Appl. Energy 2014, 132, 155-162. [CrossRef]

12. Seifert, A.H.; Rittmann, S.; Bernacchi, S.; Herwig, C. Method for Assessing the Impact of Emission Gasses on Physiology and Productivity in Biological Methanogenesis. Bioresour. Technol. 2013, 136, 747-751. [CrossRef]

13. Burkhardt, M.; Jordan, I.; Heinrich, S.; Behrens, J.; Ziesche, A.; Busch, G. Long Term and Demand-Oriented Biocatalytic Synthesis of Highly Concentrated Methane in a Trickle Bed Reactor. Appl. Energy 2019, 240, 818-826. [CrossRef]

14. Burkhardt, M.; Koschack, T.; Busch, G. Biocatalytic Methanation of Hydrogen and Carbon Dioxide in an Anaerobic Three-Phase System. Bioresour. Technol. 2015, 178, 330-333. [CrossRef] [PubMed]

15. Jensen, M.B.; Strübing, D.; de Jonge, N.; Nielsen, J.L.; Ottosen, L.D.M.; Koch, K.; Kofoed, M.V.W. Stick or Leave-Pushing Methanogens to Biofilm Formation for Ex Situ Biomethanation. Bioresour. Technol. 2019, 291, 121784. [CrossRef]

16. Nock, W.J.; Serna-Maza, A.; Heaven, S.; Banks, C.J. Evaluation of Microporous Hollow Fibre Membranes for Mass Transfer of $\mathrm{H}_{2}$ into Anaerobic Digesters for Biomethanization. J. Chem. Technol. Biotechnol. 2019, 94, 2693-2701. [CrossRef]

17. Tao, B.; Alessi, A.M.; Zhang, Y.; Chong, J.P.J.; Heaven, S.; Banks, C.J. Simultaneous Biomethanisation of Endogenous and Imported $\mathrm{CO}_{2}$ in Organically Loaded Anaerobic Digesters. Appl. Energy 2019, 247, 670-681. [CrossRef]

18. Rittmann, S.K.-M.; Seifert, A.; Herwig, C. Essential Prerequisites for Successful Bioprocess Development of Biological CH Production from CO2 and H2. Crit. Rev. Biotechnol. 2015, 35, 141-151. [CrossRef] [PubMed]

19. Rittmann, S.K.-M.R.; Seifert, A.H.; Krajete, A. Biomethanisierung—ein Prozess zur Ermöglichung der Energiewende? BIOspektrum 2014, 20, 816-817. [CrossRef]

20. Rittmann, S.K.-M.R. A Critical Assessment of Microbiological Biogas to Biomethane Upgrading Systems. In Biogas Science and Technology; Guebitz, G.M., Bauer, A., Bochmann, G., Gronauer, A., Weiss, S., Eds.; Advances in Biochemical Engineering/Biotechnology; Springer International Publishing: Cham, Switzerland, 2015; pp. 117-135. ISBN 978-3-319-21993-6.

21. Van der Stricht, W.; De Maré, C.; Plattner, T.; Fleischanderl, A.; Haselgribler, M.; Nair, P.; Wolf, C. Sustainable Production of Low Carbon, Renewable Fuels by Fermenting Industrial Process Gasses from the Iron and Steel Industry; ArcelorMittal, Primetals Technologies, LanzaTech: Gent, Belgium, 2017.

22. Safari, F.; Tavasoli, A.; Ataei, A.; Choi, J.-K. Hydrogen and Syngas Production from Gasification of Lignocellulosic Biomass in Supercritical Water Media. Int. J. Recycl. Org. Waste Agric. 2015, 4, 121-125. [CrossRef]

23. Dürre, P.; Eikmanns, B.J. C1-Carbon Sources for Chemical and Fuel Production by Microbial Gas Fermentation. Curr. Opin. Biotechnol. 2015, 35, 63-72. [CrossRef]

24. de Medeiros, E.M.; Noorman, H.; Maciel Filho, R.; Posada, J.A. Multi-Objective Sustainability Optimization of Biomass Residues to Ethanol via Gasification and Syngas Fermentation: Trade-Offs between Profitability, Energy Efficiency, and Carbon Emissions. Fermentation 2021, 7, 201. [CrossRef]

25. Phillips, J.R.; Huhnke, R.L.; Atiyeh, H.K. Syngas Fermentation: A Microbial Conversion Process of Gaseous Substrates to Various Products. Fermentation 2017, 3, 28. [CrossRef] 
26. Westman, S.Y.; Chandolias, K.; Taherzadeh, M.J. Syngas Biomethanation in a Semi-Continuous Reverse Membrane Bioreactor (RMBR). Fermentation 2016, 2, 8. [CrossRef]

27. Devarapalli, M.; Lewis, R.S.; Atiyeh, H.K. Continuous Ethanol Production from Synthesis Gas by Clostridium Ragsdalei in a Trickle-Bed Reactor. Fermentation 2017, 3, 23. [CrossRef]

28. Rittmann, S.K.-M.; Lee, H.S.; Lim, J.K.; Kim, T.W.; Lee, J.-H.; Kang, S.G. One-Carbon Substrate-Based Biohydrogen Production: Microbes, Mechanism, and Productivity. Biotechnol. Adv. 2015, 33, 165-177. [CrossRef] [PubMed]

29. Thauer, R.K. Citric-Acid Cycle, 50 Years on: Modifications and an Alternative Pathway in Anaerobic Bacteria. Eur. J. Biochem. 1988, 176, 497-508. [CrossRef]

30. Klasson, K.; Cowger, J.; Ko, C.; Vega, J.; Clausen, E.; Gaddy, J. Methane Production from Synthesis Gas Using a Mixed Culture OfR. Rubrum M. Barkeri, and M. Formicicum. Appl. Biochem. Biotechnol. 1990, 24, 317-328. [CrossRef]

31. Daniels, L.; Fuchs, G.; Thauer, R.; Zeikus, J. Carbon Monoxide Oxidation by Methanogenic Bacteria. J. Bacteriol. 1977, 132, 118-126. [CrossRef]

32. O'Brien, J.M.; Wolkin, R.; Moench, T.; Morgan, J.; Zeikus, J. Association of Hydrogen Metabolism with Unitrophic or Mixotrophic Growth of Methanosarcina Barkeri on Carbon Monoxide. J. Bacteriol. 1984, 158, 373-375. [CrossRef]

33. Diender, M.; Pereira, R.; Wessels, H.J.; Stams, A.J.; Sousa, D.Z. Proteomic Analysis of the Hydrogen and Carbon Monoxide Metabolism of Methanothermobacter Marburgensis. Front. Microbiol. 2016, 7, 1049. [CrossRef]

34. Diender, M.; Uhl, P.S.; Bitter, J.H.; Stams, A.J.; Sousa, D.Z. High Rate Biomethanation of Carbon Monoxide-Rich Gases via a Thermophilic Synthetic Coculture. ACS Sustain. Chem. Eng. 2018, 6, 2169-2176. [CrossRef]

35. Kohlmayer, M.; Robert, H.; Raimund, B.; Wolfgang, M. Simultaneous $\mathrm{CO}_{2}$ and CO methanation using microbes. Microbiology 2018. [CrossRef]

36. Schmider, T. Ecophysiology and Methane Productivity of Carboxydotrophy-Based Archael Co-Cultures. Master's Thesis, University of Vienna, Vienna, Austria, 2018.

37. Kim, M.-S.; Fitriana, H.N.; Kim, T.W.; Kang, S.G.; Jeon, S.G.; Chung, S.H.; Park, G.W.; Na, J.-G. Enhancement of the Hydrogen Productivity in Microbial Water Gas Shift Reaction by Thermococcus Onnurineus NA1 Using a Pressurized Bioreactor. Int. J. Hydrog. Energy 2017, 42, 27593-27599. [CrossRef]

38. Lee, S.H.; Kim, M.-S.; Lee, J.-H.; Kim, T.W.; Bae, S.S.; Lee, S.-M.; Jung, H.C.; Yang, T.-J.; Choi, A.R.; Cho, Y.-J.; et al. Adaptive Engineering of a Hyperthermophilic Archaeon on CO and Discovering the Underlying Mechanism by Multi-Omics Analysis. Sci. Rep. 2016, 6, 22896. [CrossRef]

39. Kim, M.-S.; Bae, S.S.; Kim, Y.J.; Kim, T.W.; Lim, J.K.; Lee, S.H.; Choi, A.R.; Jeon, J.H.; Lee, J.-H.; Lee, H.S.; et al. CO-Dependent H 2 Production by Genetically Engineered Thermococcus Onnurineus NA1. Appl. Environ. Microbiol. 2013, 79, 2048-2053. [CrossRef] [PubMed]

40. Bae, S.S.; Kim, T.W.; Lee, H.S.; Kwon, K.K.; Kim, Y.J.; Kim, M.-S.; Lee, J.-H.; Kang, S.G. H2 Production from CO, Formate or Starch Using the Hyperthermophilic Archaeon, Thermococcusonnurineus. Biotechnol. Lett. 2012, 34, 75-79. [CrossRef] [PubMed]

41. Bae, S.-S.; Kim, Y.-J.; Yang, S.-H.; Lim, J.-K.; Jeon, J.-H.; Lee, H.-S.; Kang, S.-G.; Kim, S.; Lee, J. Thermococcus onnurineus Sp. Nov., a Hyperthermophilic Archaeon Isolated from a Deep-Sea Hydrothermal Vent Area at the PACMANUS Field. J. Microbiol. Biotechnol. 2006, 16, 1826.

42. Bellack, A.; Huber, H.; Rachel, R.; Wanner, G.; Wirth, R. Methanocaldococcus villosus Sp. Nov., a Heavily Flagellated Archaeon That Adheres to Surfaces and Forms Cell-Cell Contacts. Int. J. Syst. Evol. Microbiol. 2011, 61, 1239-1245. [CrossRef] [PubMed]

43. Jeanthon, C.; l'Haridon, S.; Reysenbach, A.-L.; Corre, E.; Vernet, M.; Messner, P.; Sleytr, U.; Prieur, D. Methanococcus vulcanius Sp. Nov., a Novel Hyperthermophilic Methanogen Isolated from East Pacific Rise, and Identification of Methanococcus Sp. DSM 4213Tas Methanococcus fervens Sp. Nov. Int. J. Syst. Evol. Microbiol. 1999, 49, 583-589. [CrossRef]

44. Jones, W.; Leigh, J.; Mayer, F.; Woese, C.; Wolfe, R. Methanococcus jannaschii Sp. Nov., an Extremely Thermophilic Methanogen from a Submarine Hydrothermal Vent. Arch. Microbiol. 1983, 136, 254-261. [CrossRef]

45. Diender, M.; Stams, A.J.; Sousa, D.Z. Pathways and Bioenergetics of Anaerobic Carbon Monoxide Fermentation. Front. Microbiol. 2015, 6, 1275. [CrossRef]

46. Balch, W.E.; Wolfe, R. New Approach to the Cultivation of Methanogenic Bacteria: 2-Mercaptoethanesulfonic Acid (HSCoM)-Dependent Growth of Methanobacterium Ruminantium in a Pressureized Atmosphere. Appl. Environ. Microbiol. 1976, 32, 781-791. [CrossRef]

47. Taubner, R.-S.; Rittmann, S.K.-M. Method for Indirect Quantification of $\mathrm{CH}_{4}$ Production via $\mathrm{H}_{2} \mathrm{O}$ Production Using Hydrogenotrophic Methanogens. Front. Microbiol. 2016, 7, 532. [CrossRef]

48. Rittmann, S.K.-M.; Herwig, C. A Comprehensive and Quantitative Review of Dark Fermentative Biohydrogen Production. Microb. Cell Factories 2012, 11, 115. [CrossRef] [PubMed]

49. Pappenreiter, P.A.; Zwirtmayr, S.; Mauerhofer, L.-M.; Rittmann, S.K.-M.R.; Paulik, C. Development of a Simultaneous Bioreactor System for Characterization of Gas Production Kinetics of Methanogenic Archaea at High Pressure. Eng. Life Sci. 2019, 19, 537-544. [CrossRef] [PubMed]

50. Rittmann, S.K.-M.; Seifert, A.; Herwig, C. Quantitative Analysis of Media Dilution Rate Effects on Methanothermobacter Marburgensis Grown in Continuous Culture on $\mathrm{H}_{2}$ and $\mathrm{CO}_{2}$. Biomass Bioenergy 2012, 36, 293-301. [CrossRef]

51. Bernacchi, S.; Rittmann, S.K.-M.; Seifert, A.H.; Krajete, A.; Herwig, C. Experimental Methods for Screening Parameters Influencing the Growth to Product Yield $\left(\mathrm{Y}\left(\mathrm{x} / \mathrm{CH}_{4}\right)\right)$ of a Biological Methane Production (BMP) Process Performed with Methanothermobacter Marburgensis. AIMS Bioeng. 2014, 1, 72-86. [CrossRef]

52. Reischl, B.; Ergal, İ.; Rittmann, S.K.-M. Biohydrogen Production Characteristics of Desulfurococcus Amylolyticus DSM 16532. Int. J. Hydrog. Energy 2018, 43, 8747-8753. [CrossRef] 
53. Pruckner, C. Evolutionary and Physiological Aspects of Potentially Carboxydotrophic Archaea. Master's Thesis, University of Vienna, Vienna, Austria, 2019.

54. Pfeifer, K.; Ergal, İ.; Koller, M.; Basen, M.; Schuster, B.; Rittmann, S.K.-M.R. Archaea Biotechnology. Biotechnol. Adv. 2021, 47, 107668. [CrossRef]

55. Ergal, İ; Bochmann, G.; Fuchs, W.; Rittmann, S.K.-M.R. Design and Engineering of Artificial Microbial Consortia for Biohydrogen Production. Curr. Opin. Biotechnol. 2022, 73, 74-80. [CrossRef]

56. Guiot, S.R.; Cimpoia, R.; Carayon, G. Potential of Wastewater-Treating Anaerobic Granules for Biomethanation of Synthesis Gas. Environ. Sci. Technol. 2011, 45, 2006-2012. [CrossRef]

57. Straub, C.T.; Counts, J.A.; Nguyen, D.M.N.; Wu, C.-H.; Zeldes, B.M.; Crosby, J.R.; Conway, J.M.; Otten, J.K.; Lipscomb, G.L.; Schut, G.J.; et al. Biotechnology of Extremely Thermophilic Archaea. FEMS Microbiol. Rev. 2018, 42, 543-578. [CrossRef] 